\title{
Analysis of cultivable microbiota and diet intake pattern of the long-lived naked mole-rat
}

\author{
Tewodros Debebe ${ }^{1,2,9}$, Susanne Holtze ${ }^{5}$, Michaela Morhart ${ }^{5}$, Thomas Bernd Hildebrandt ${ }^{5}$, Steffen Rodewald ${ }^{3}$, \\ Klaus Huse ${ }^{6}$, Matthias Platzer ${ }^{6}$, Dereje Wyohannes ${ }^{7}$, Salomon Yirga ${ }^{7}$, Alemayehu Lemma ${ }^{8}$, Rene Thieme ${ }^{4}$, \\ Brigitte König ${ }^{2}$ and Gerd Birkenmeier ${ }^{1 *}$
}

\begin{abstract}
Background: A variety of microbial communities exist throughout the human and animal body. Genetics, environmental factors and long-term dietary habit contribute to shaping the composition of the gut microbiota. For this reason the study of the gut microbiota of a mammal exhibiting an extraordinary life span is of great importance. The naked mole-rat (Heterocephalus glaber) is a eusocial mammal known for its longevity and cancer resistance.

Methods: Here we analyzed its gut microbiota by cultivating the bacteria under aerobic and anaerobic conditions and identifying their species by mass spectrometry.

Results: Altogether, 29 species of microbes were identified, predominantly belonging to Firmicutes, and Bacteroidetes. The most frequent species were Bacillus megaterium (45.2 \%), followed by Bacteroides thetaiotaomicron (19.4\%), Bacteroides ovatus, Staphylococcus sciuri and Paenibacillus spp., each with a frequency of $16.1 \%$.

Conclusion: Overall, the gut of the naked mole-rat is colonized by diverse, but low numbers of cultivable microbes compared with humans and mice. The primary food plants of the rodents are rich in polyphenols and related compounds, possessing anti-microbial, anti-inflammatory, anti-oxidative as well as anti-cancer activity which may contribute to their exceptionally healthy life.
\end{abstract}

Keywords: Naked mole-rat, Microbiota, Diet, Polyphenols

\section{Background}

The microbiota is defined as the entity of microbial communities, which colonize different parts of the body of a host organism. These habitats include among others, the gut, oral cavity, skin, eyes and vagina [1]. Increasing evidence supports the notion that the microbiota has a strong influence on health and disease in humans $[2,3]$. Recent studies have concluded that the composition and function of microbiota play a significant role in autoimmunity and immune regulation, development of cancer, Crohn's disease, obesity, and type 1 and 2 diabetes

\footnotetext{
*Correspondence: gerd.birkenmeier@medizin.uni-leipzig.de

${ }^{1}$ Medical Faculty, Institute of Biochemistry, University of Leipzig,

Johannisallee 30, 04103 Leipzig, Germany

Full list of author information is available at the end of the article
}

[4-7]. This causal relationship came currently in the focus of scientific interest. Analyzing the composition, function, and distribution of the microbiota in relation to diet, environment, genetic factors, and host immunity will help to elucidate the pivotal role of the microbiota in health and pathogenesis of diseases. The naked mole-rat (Heterocephalus glaber) is a eusocial mammalian species that lives in colonies of up to 300 individuals. For this mouse-sized subterranean rodent a life span of about 30 years has been reported for both, reproductive and non-reproductive castes. Moreover, it is known to appear healthy over its life span, displays resistance to oxidative stress and is remarkably resistant to both spontaneous cancer and experimentally induced tumorigenesis [8]. However, the recent report of two cases of cancer in zoo-housed naked mole-rats may not alter 
the longstanding observation of cancer resistance of these animals [9]. A recent study has shown that captive naked mole-rats have higher levels of oxidative damage and decreased level of anti-oxidants compared to short-lived mice, indicating the involvement of further mechanisms known to counter high levels of oxidative damage [10]. Thus, naked mole-rats pose a challenge to the current theories that link aging, cancer and redox homeostasis. For these reasons as well as their close phylogenetic relation to humans, naked mole-rats are of special interest in the search for mechanisms leading to a particularly long and healthy life [11]. Recent publications demonstrate a strong link between different diseases and gut microbiota. This prompted us to investigate the gut microbiota of the naked mole-rat to obtain deeper insights into their astonishing longevity. Therefore, for the first time, we analyzed and characterized cultivable gut microbes obtained from the intestine and feces of wild naked mole-rats. Furthermore, we assessed the main diet of the animal in the wild and discuss their constituents in relation to their medical significance.

\section{Methods}

\section{Naked mole-rat sampling}

Eleven wild naked mole-rats from the Rift Valley of Ethiopia were captured and detained. Intestinal and fecal samples of the animals were obtained from individuals captured in Ethiopia. Permission comprising both, field permit and ethics approval was granted by the Ethiopian Wildlife Conservation Authority (EWCA; ref. No. 31/394/07 dated 27 November 2014). Intestinal content and feces were collected and immediately frozen in liquid nitrogen until further analysis. Animal collection and sampling were performed in accordance with the approved guideline and regulation of the national wildlife authority of Ethiopia.

\section{Microbial growth conditions}

Following standard aseptic procedures, samples of the colon, cecum and feces from naked mole-rats were subjected to microbial identification. One gram of intestine and feces of each animal were weighed and thoroughly dispersed and homogenized by vortex in $3 \mathrm{~mL}$ of sterile saline $(0.85 \%)$ (bioMérieux, Marcy I'Etoile, France) for $1 \mathrm{~min}$ and tenfold serial dilutions were made subsequently. Next, from each dilution $0.1 \mathrm{~mL}$ aliquot was plated onto blood agar (Carl Roth GmbH, Karlsruhe, Germany) and Brucella blood agar (Becton, Dickinson, Sparks, MD, USA) and incubated at $37^{\circ} \mathrm{C}$ for $24-72 \mathrm{~h}$ at ambient air or anaerobically, respectively. Following incubation, the growth of bacteria was recorded and the number of colonies was counted based on their morphology.
The colonies were further sub-cultured individually to obtain pure cultures. Subsequently, each of the pure colonies was identified by matrix-assisted laser desorption ionization time-of-flight (MALDI-TOF) mass spectrometry and gram staining was performed for each pure culture as a cross check with the MALDI-TOF results.

\section{MALDI-TOF-MS based microbe identification}

The automated MALDI-TOF was performed following the standard protocol (bioMérieux, Marcy I'Etoile, France). Freshly grown pure microbial cells from a single colony and a control (Escherichia coli) were deposited onto the target slides and to each, $1 \mu \mathrm{L}$ of the $\alpha$-cyano-4hydroxycinnamic acid (CHCA) matrix solution $\left(\right.$ VITEK $^{\circledR}$ MS-CHCA REF 411071, bioMérieux, Marcy I'Etoile, France) was added. After solvent evaporation at room temperature, the slides were inserted into the device and analyzed (VITEK ${ }^{\circledR}$-MS, Marcy I'Etoile, France). Finally, sample spectra were compared to an extensive database of known bacterial species by VITEK $^{\circledR}$-MS proofing, allowing us to accurately identify the microorganism in question.

\section{Microbial inoculum preparation}

Bacillus megaterium, Staphylococcus scuiri, Parabacteroides distasonis, Clostridium ramosum, Bacteroides ovatus from the naked mole-rat and two clinical human pathobionts, E. coli and Staphylococcus aureus were maintained on blood agar or Brucella blood agar at $37{ }^{\circ} \mathrm{C}$ for $24-48 \mathrm{~h}$ aerobically or anaerobically, respectively. Following incubation, isolates were adjusted to McFarland $0.5\left(\sim 10^{8}\right.$ cells $\left./ \mathrm{mL}\right)$ in a $0.85 \%$ saline solution. Subsequently, standardized microbial suspension at low $\left(10^{3}\right.$ cells $\left./ \mathrm{mL}\right)$ and high $\left(10^{6}\right.$ cells $\left./ \mathrm{mL}\right)$ concentrations were prepared in Roswell Park Memorial Institute (RPMI)-1640 medium.

\section{Whole blood assay}

Heparinized blood was obtained from healthy human volunteers and stimulated by lipopolysaccharide (LPS) E. coli 0111:B4 (10 ng/ml) (SigmaAldrich; Taufkirchen, Germany) as previously described [12]. Standardized live microbial suspension at low $\left(10^{3}\right.$ cells $\left./ \mathrm{mL}\right)$ or high $\left(10^{6}\right.$ cells $\left./ \mathrm{mL}\right)$ final concentrations were mixed with $200 \mu \mathrm{L}$ heparinized human blood contained in a total volume of $800 \mu \mathrm{L}$ RPMI-medium in 24-well culture plates (Cellstar ${ }^{\circledR}$ Greiner Bio-One, Frickenhausen, Germany) at $37{ }^{\circ} \mathrm{C}$ and $5 \% \mathrm{CO}_{2}$ for $8 \mathrm{~h}$. Following incubation, the suspension was transferred into fresh sterile $1.5 \mathrm{~mL}$ micro centrifuge tubes and centrifuged at $13,000 \times g$ for $5 \mathrm{~min}$. Finally, plasma supernatants were harvested and stored at $-20{ }^{\circ} \mathrm{C}$. The local ethics committee of the Faculty of Medicine of the University of Leipzig, Germany, 
approved this study in accordance to the ICH-GCP guidelines (Reference No.: 057-2010-08032010). Written informed consent was obtained from all subjects and the experiments were performed in accordance with the guidelines and regulation of the Medical Faculty of the University of Leipzig.

\section{Cytometry bead array assay}

Assessment of cytokine levels in plasma supernatants of human blood cell cultures was performed according to the manufacturer's instruction using cytometry bead array (CBA) immunoassay as previously described [12]. The data were analyzed using a FACS Calibur and the CellQuest ${ }^{\mathrm{TM}}$ Software (BD Biosciences).

\section{Feeding trials and analysis of biochemical constituents of the wild naked mole-rat's diet}

Different plant species that are distributed nearby the habitat of the animals were freshly collected. Feeding trials were performed on captured members of the colony temporarily managed near Hawassa, South Ethiopia. Within this trial the degree of consumption of the plant species offered to the animals was recorded and categorized as either main diet, or rarely consumed food source. In order to investigate the constituents and medical significance of the plant species consumed by the animals in the wild, a systematic review of the appropriate literature was performed. At first, the scientific name of all plant species was verified. To fulfill this special assignment, we used the dynamic checklist of the catalogue of life (www. catalogueoflife.org). For analyzing the chemical content of identified plants the database scifinder (www.cas. org) was used. Dependent on the subject of search, the number of the proven sources differed from nil to over 10,000, for instance the common crops Ipomoea batatas (sweet potato) and Arachis hypogaea (groundnut) are well-described whereas two plants, Aloe trichosantha and Endostemon tenuiflorus are rarely described. Therefore, for these species the chemical content and bioactive substances were suggested by comparing them with the higher-ranking genus and family only $[13,14]$.

\section{Data analysis}

The data obtained were analyzed in terms of descriptive statistics. Characteristics of each isolates, the constituent and medicinal values of plant species were systematically reviewed. One way ANOVA and Student's $t$ test were used to analyze the mean difference in cytokine levels for each group of microbes compared with negative control and LPS-stimulated samples using GraphPad Prism version 5 (San Diego, CA, USA) and plotted as mean \pm SEM. $p$ value $<0.05$ was considered statistically significant.

\section{Results}

Frequency of microbes isolated from wild naked mole-rats In the present study, we identified the composition of gut microbes of the naked mole-rat (Table 1). Overall, 29 different species of microbes were identified from the colon, cecum and feces of wild naked mole-rats. The principal microorganisms of the naked mole-rats belong to the phylum Firmicutes (58.6\%), followed by Bacteroidetes (20.7 \%). Less frequently identified phyla were, Proteobacteria (10.3\%), Actinobacteria (6.9\%) and Ascomycota $(3.5 \%)$. The amounts of cultivable microbes ranged from $10^{2}$ to $5 \times 10^{5}, 10^{2}-10^{5}$, and $10^{2}-3 \times 10^{5}$ c.f.u. $/ g$ in cecum, colon, and feces, respectively. In total, the most frequently occurring species were $B$. megaterium (45.2\%), followed in order by Bacteroides thetaiotaomicron (19.4 \%), B. ovatus, Paenibacillus spp., Staphylococcus scuiri each with a frequency of $16.1 \%$, Staphylococcus gallinarum (12.9\%) and Enterobacter cloacae/asburiae (12.9\%). The remaining isolates were least identified with percentages ranging from 3.2 to $9.7 \%$.

The intestinal content particularly colon, cecum and feces of the naked mole-rat obtained from the wild were cultivated under aerobic and anaerobic conditions. The table illustrates the species name, phylum name, cultivable amount of microbial cells and characteristics of the isolated microbiota referring to their host. Normal flora is described as a relatively stable microbial community that routinely inhabits in and on the body of a wide range of animal species. Colony-forming unit (c.f.u.).

\section{Occurrence of microbes within different intestinal compartments of wild naked mole-rats}

The most frequently isolated species in all intestinal specimens were $B$. megaterium followed in descending prevalence by Bacteroides thetaiotaomicron, B. ovatus, and Staphylococcus sciuri in colon, cecum and feces. Paenibacillus spp., Enterobacter cloacae/asburiae, S. gallinarum, Actinomyces viscosus, Bacteroides vulgatus, Staphylococcus xylosus were identified from colon and cecum. Whereas P. distasonis, Bacillus simplex, Staphylococcus cohnii spp. urealyticus, and Staphylococcus arlettae were isolated from colon and feces. Except Lysinibacillus fusiformis, which was identified from cecum and feces, the remaining species were mono-isolates with a frequency of $3.2 \%$ (Table 2 ).

\section{Habitat and diet of wild naked mole-rats}

According to continuous field observations, the main habitat of the naked mole-rat is characterized by arid vegetation such as shrubs and desert bush covered areas, which is located in arid zones of the Eastern and Southern Ethiopia. Naked mole-rat colonies dig extensive underground burrow systems, which they rarely 
Table 1 Distribution of the identified microbiota from the wild naked mole-rats $(n=11)$

\begin{tabular}{|c|c|c|c|c|}
\hline Sites & Species & Phylum & (c.f.u./g) in range & Characterstics $^{\mathrm{a}}$ \\
\hline \multirow[t]{20}{*}{ Colon } & Staphylococcus sciuri & Firmicutes & $1 \times 10^{2}-10^{3}$ & Normal flora \\
\hline & Staphylococcus cohnii spp. urealyticus & Firmicutes & $1-2 \times 10^{3}$ & Normal flora \\
\hline & Staphylococcus arlettae & Firmicutes & $3 \times 10^{2}$ & Normal flora \\
\hline & Staphylococcus gallinarum & Firmicutes & $2 \times 10^{2}-3 \times 10^{3}$ & Normal flora \\
\hline & Staphylococcus hyicus & Firmicutes & $3 \times 10^{2}$ & Normal flora \\
\hline & Staphylococcus xylosus & Firmicutes & $3 \times 10^{2}$ & Normal flora \\
\hline & Bacillus megaterium & Firmicutes & $0.2-1 \times 10^{4}$ & Normal flora \\
\hline & Bacillus subtilus/amyloliquefaciens & Firmicutes & $1 \times 10^{2}$ & Normal flora \\
\hline & Bacillus pumilus & Firmicutes & $1 \times 10^{3}$ & Normal flora \\
\hline & Bacillus simplex & Firmicutes & $2 \times 10^{3}$ & Normal flora \\
\hline & Paenibacillus spp. & Firmicutes & $2-3 \times 10^{2}$ & Normal flora \\
\hline & Paenibacillus pabuli & Firmicutes & $1 \times 10^{2}$ & Normal flora \\
\hline & Bacteroides ovatus & Bacteroidetes & $1-2 \times 10^{3}$ & Normal flora \\
\hline & Bacteroides thetaiotaomicron & Bacteroidetes & $1-4 \times 10^{5}$ & Normal flora \\
\hline & Parabacteroides distasonis & Bacteroidetes & $1 \times 10^{3}$ & Normal flora \\
\hline & Bacteroides vulgatus & Bacteroidetes & $5 \times 10^{5}$ & Normal flora \\
\hline & Kluyvera ascorbata & Proteobacteria & $3 \times 10^{3}$ & Normal flora \\
\hline & Klebsiella pneumoniae & Proteobacteria & $2 \times 10^{2}$ & Normal flora \\
\hline & Enterobacter cloacae/asburiae & Proteobacteria & $5 \times 10^{3}-10^{5}$ & Normal flora \\
\hline & Actinomyces viscosus & Actinobacteria & $1 \times 10^{3}$ & Normal flora \\
\hline \multirow[t]{18}{*}{ Cecum } & Bacillus megaterium & Firmicutes & $2-4 \times 10^{3}$ & Normal flora \\
\hline & Staphylococcus gallinarum & Firmicutes & $0.4-1 \times 10^{3}$ & Normal flora \\
\hline & Staphylococcus xylosus & Firmicutes & $3 \times 10^{2}$ & Normal flora \\
\hline & Staphylococcus sciuri & Firmicutes & $1 \times 10^{3}$ & Normal flora \\
\hline & Paenibacillus spp. & Firmicutes & $0.1-1 \times 10^{4}$ & Normal flora \\
\hline & Staphylococcus warneri & Firmicutes & $1 \times 10^{3}$ & Normal flora \\
\hline & Brevibacillus spp. & Firmicutes & $4 \times 10^{2}$ & Normal flora \\
\hline & Lysinibacillus fusiformis & Firmicutes & $2 \times 10^{2}$ & Normal flora \\
\hline & Streptococcus mitis/oralis & Firmicutes & $2 \times 10^{2}$ & Normal flora \\
\hline & Enterococcus casseliflavus & Firmicutes & $1 \times 10^{3}$ & Normal flora \\
\hline & Bacteroides ovatus & Bacteroidetes & $0.1-1.2 \times 10^{4}$ & Normal flora \\
\hline & Bacteroides thetaiotaomicron & Bacteroidetes & $0.2-1 \times 10^{5}$ & Normal flora \\
\hline & Bacteroides fragilis & Bacteroidetes & $2 \times 10^{3}$ & Normal flora \\
\hline & Bacteroides vulgatus & Bacteroidetes & $1 \times 10^{5}$ & Normal flora \\
\hline & Enterobacter cloacae/asburiae & Proteobacteria & $0.7-2 \times 10^{3}$ & Normal flora \\
\hline & Actinomyces viscosus & Actinobacteria & $1 \times 10^{2}$ & Normal flora \\
\hline & Rhodococcus rhodochrous & Actinobacteria & $1 \times 10^{2}$ & Normal flora \\
\hline & Candida tropicalis & Ascomycota & $1 \times 10^{3}$ & Normal flora \\
\hline \multirow[t]{11}{*}{ Feces } & Lysinibacillus fusiformis & Firmicutes & $1 \times 10^{2}$ & Normal flora \\
\hline & Bacillus simplex & Firmicutes & $1 \times 10^{3}$ & Normal flora \\
\hline & Bacillus megaterium & Firmicutes & $0.2-3 \times 10^{5}$ & Normal flora \\
\hline & Clostridium ramosum & Firmicutes & $2 \times 10^{2}$ & Normal flora \\
\hline & Staphylococcus sciuri & Firmicutes & $1-2 \times 10^{3}$ & Normal flora \\
\hline & Staphylococcus cohnii spp. urealyticus & Firmicutes & $1 \times 10^{3}$ & Normal flora \\
\hline & Staphylococcus arlettae & Firmicutes & $1 \times 10^{2}$ & Normal flora \\
\hline & Bacteriodes unifromis & Bacteroidetes & $3 \times 10^{2}$ & Normal flora \\
\hline & Bacteroides thetaiotaomicron & Bacteroidetes & $2 \times 10^{3}$ & Normal flora \\
\hline & Bacteriodes ovatus & Bacteroidetes & $1 \times 10^{3}$ & Normal flora \\
\hline & Parabacteroides distasonis & Bacteroidetes & $1-3 \times 10^{3}$ & Normal flora \\
\hline
\end{tabular}

\footnotetext{
a Sources: [15-19]
} 
Table 2 Frequency of microbes in colon, cecum and feces of the naked mole-rats

\begin{tabular}{|c|c|c|c|c|}
\hline \multirow[t]{2}{*}{ Species } & \multicolumn{4}{|c|}{ Number of positive isolates (\% isolation frequency) } \\
\hline & Colon $(n=10)$ & Cecum $(n=11)$ & Feces $(n=10)$ & Total \\
\hline Bacillus megaterium & $5(50)$ & $5(45.5)$ & $4(40)$ & $14(45.2)$ \\
\hline Staphylococcus sciuri & $2(20)$ & $1(9.1)$ & $2(20)$ & $5(16.1)$ \\
\hline Bacteroides thetaiotaomicron & $2(20)$ & $3(27.3)$ & $1(10)$ & $6(19.4)$ \\
\hline Bacillus simplex & $1(10)$ & $0(0)$ & $1(10)$ & $2(6.5)$ \\
\hline Staphylococcus gallinarum & $2(20)$ & $2(18.2)$ & $0(0)$ & $4(12.9)$ \\
\hline Lysinibacillus fusiformis & $0(0)$ & $1(9.1)$ & $1(10)$ & $2(6.5)$ \\
\hline Paenibacillus spp. & $3(30)$ & $2(18.2)$ & $0(0)$ & $5(16.1)$ \\
\hline Staphylococcus cohnii spp. urealyticus & $2(20)$ & $0(0)$ & $1(10)$ & $3(9.7)$ \\
\hline Enterobacter cloacae/asburiae & $2(20)$ & $2(18.2)$ & $0(0)$ & $4(12.9)$ \\
\hline Bacteroides ovatus & $1(10)$ & $2(18.2)$ & $2(20)$ & $5(16.1)$ \\
\hline Actinomyces viscosus & $1(10)$ & $1(9.1)$ & $0(0)$ & $2(6.5)$ \\
\hline Parabacteroides distasonis & $1(10)$ & $0(0)$ & $2(20)$ & $3(9.7)$ \\
\hline Bacteroides vulgatus & $1(10)$ & $1(9.1)$ & $0(0)$ & $2(6.5)$ \\
\hline Staphylococcus xylosus & $1(10)$ & $1(9.1)$ & $0(0)$ & $2(6.5)$ \\
\hline Clostridium ramosum & $0(0)$ & $0(0)$ & $1(10)$ & $1(3.2)$ \\
\hline Bacteroides fragilis & $0(0)$ & $1(9.1)$ & $0(0)$ & $1(3.2)$ \\
\hline Staphylococcus arlettae & $1(10)$ & $0(0)$ & $1(10)$ & $2(6.5)$ \\
\hline Brevibacillus spp. & $0(0)$ & $1(9.1)$ & $0(0)$ & $1(3.2)$ \\
\hline Staphylococcus hyicus & $1(10)$ & $0(0)$ & $0(0)$ & $1(3.2)$ \\
\hline Rhodococcus rhodochrous & $0(0)$ & $1(9.1)$ & $0(0)$ & $1(3.2)$ \\
\hline Bacteroides unifromis & $0(0)$ & $0(0)$ & $1(10)$ & $1(3.2)$ \\
\hline Staphylococcus warneri & $0(0)$ & $1(9.1)$ & $0(0)$ & $1(3.2)$ \\
\hline Enterococcus casseliflavus & $0(0)$ & $1(9.1)$ & $0(0)$ & $1(3.2)$ \\
\hline Bacillus subtilus/amyloliquefaciens & $1(10)$ & $0(0)$ & $0(0)$ & $1(3.2)$ \\
\hline Bacillus pumilus & $1(10)$ & $0(0)$ & $0(0)$ & $1(3.2)$ \\
\hline Klebsiella pneumoniae & $1(10)$ & $0(0)$ & $0(0)$ & $1(3.2)$ \\
\hline Kluyvera ascorbata & $1(10)$ & $0(0)$ & $0(0)$ & $1(3.2)$ \\
\hline Streptococcus mitis/oralis & $0(0)$ & $1(9.1)$ & $0(0)$ & $1(3.2)$ \\
\hline Candida tropicalis & $0(0)$ & $1(9.1)$ & $0(0)$ & $1(3.2)$ \\
\hline
\end{tabular}

leave. The type of diet consumed by the rodents was assessed. Naturally occurring plant species were found to be rich in flavonoids, essential fatty acid, solanine alkaloids, carotenoids, tannins, starch, fiber, vitamins, cafeic acid derivatives and others [20-32] (Additional file 1: Table S1).

\section{Innate immune cytokine profiles upon stimulation} of human whole blood by microbes of the naked mole-rat Microbes are known to cross the gut barrier and possibly induce inflammatory responses in different organs [4]. Therefore, we asked to what extent microbes of the naked mole-rat are capable to stimulate the innate immune system of humans in an ex vivo setting in comparison to bacteria present in the human gut. For that heparinized human blood was mixed with a defined number of microbial cells, specifically $B$. megaterium, S. sciuri, $P$. distasonis, $C$. ramosum and B. ovatus at low $\left(10^{3}\right.$ cells $\left./ \mathrm{mL}\right)$ and high $\left(10^{6}\right.$ cells $\left./ \mathrm{mL}\right)$, concentrations respectively, and incubated at $37^{\circ} \mathrm{C}$ for $8 \mathrm{~h}$. Stimulation by $10 \mathrm{ng}$ LPS was carried on to verify the viability and responsiveness of the white blood cells. Accordingly, at a low concentration of naked mole-rat bacterial cells no release of cytokines could be observed as exemplified for interleukin-1ß (IL-1ß) (Fig. 1). In contrast, using equivalent numbers of the pathobionts E. coli and S. aureus, an augmented release of IL-1 $\beta$ versus control was observed $(p<0.05)$. Likewise, a similar trend was seen with respect to tumor necrosis factor- $\alpha$ (TNF- $\alpha$ ) and low concentrations of gut microbes. As expected, stimulation by E. coli and $S$. aureus induced a remarkable release of TNF- $\alpha$ from human white blood cells versus control ( $\mathrm{p}<0.05)$. In contrast, a low number of microbes was found to significantly induce IL-6, except $B$. megaterium. Again, this contrasts the strong effect of $E$. coli on this inflammatory cytokine $(\mathrm{p}<0.05)$. 


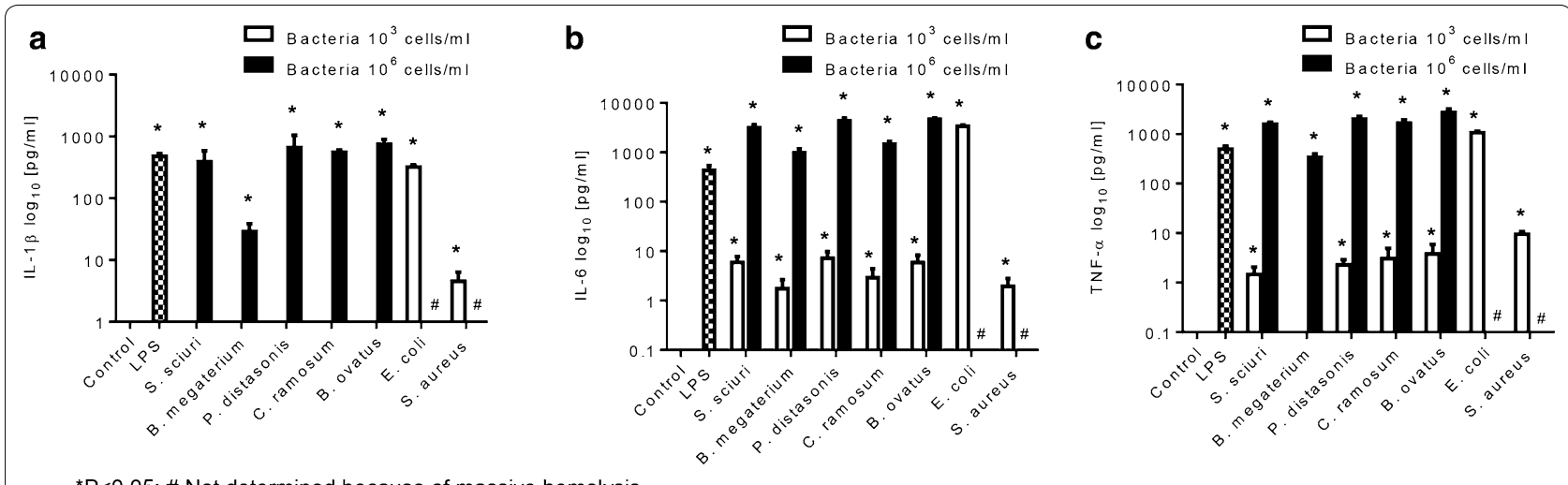

Fig. 1 Stimulation of inflammatory cytokines by naked mole-rat microbes. Heparinized blood from healthy volunteers was stimulated by medium alone (negative control), LPS (positive control), S. sciuri, B. megaterium, P. distasonis, C. ramosum, B. ovatus and two human pathobionts E. coli and S. aureus at $37^{\circ} \mathrm{C}$ and $5 \% \mathrm{CO}_{2}$ for $8 \mathrm{~h}$. The levels of the cytokines IL-1 $\beta(\mathbf{a})$, TNF-a $(\mathbf{b}), \mathrm{LL}-6(\mathbf{c})$ were measured by cytometric bead array assays. The experiment was done in triplicates and data are expressed as mean $\pm \mathrm{SEM} .{ }^{*} \mathrm{p}<0.05$; " ${ }^{\text {strong hemolysis }}$

Higher number of microbes causes an enhanced release of inflammatory cytokines as manifested for IL-1 $\beta$, TNF$\alpha$, and IL-6 $(\mathrm{p}<0.05)$ respectively, irrespective of the type of isolates (Fig. 1a-c). With exception of B. megaterium $(\mathrm{p}<0.05)$ all other isolates caused an elevated response of IL-1 $\beta$ and TNF- $\alpha$. Moreover, B. megaterium was found to induce less IL-6 release compared to other microbes. Unfortunately, high concentration of E. coli and S. aureus could not be tested as they caused massive hemolysis of the blood that resulted in the incapability of the cells to secret cytokines.

\section{Discussion}

The human intestine is believed to contain approximately 100 trillion intestinal (gut) microbiota comprising about 500-1000 different species [33]. These intestinal microbiota exist in a symbiotic relationship with their host, by metabolizing compounds that the host is unable to utilize and controlling the immune balance of the host's body. However, the composition of the intestinal microbiota is known to vary, depending on diet, nutritional status, and other factors. It has been recognized that the intestinal microbiota is involved in the pathogenesis of diverse diseases not only in the intestine but also in organs distant from the intestine. Thus, the intestinal microbiota might contribute to the onset of diseases such as cancer by the pro-carcinogenic activities of specific pathogens and by synthesis of bacterial metabolites circulating in the host's body, as well. For instance, mice supplemented orally with certain bacteria in early life were resistant to oncogeneassociated mammary carcinogenesis later in life [34].

Resistance to cancer and extraordinary life span are hallmarks of the naked mole-rat [35]. Therefore, it was our aim to investigate the composition of the cultivable microbiota of these animals. Our results show that in wild naked mole-rats, Firmicutes and Bacteroidetes were consistently found in highest number. Similarly, previous studies in humans suggested that Firmicutes and Bacteroides are among the dominant enterotypes of the gut microbiota of most mammals across a wide range of species [36]. For the naked mole-rat we found a ratio of Firmicutes to Bacteroidetes of $8 / 1$, which is similar to one found in healthy human adults of 10/1 [15]. For comparison, in obese adults the ratio rises to $100 / 1$ and drops to $1 / 1$ in people with chronic inflammatory bowel disease [37]. Interestingly, the phylum Proteobacteria, which comprises a wide range of potential pathogens [38] was among the less identified microbiota of the naked molerat. Moreover, most microbes identified were found to be the normal flora, suggesting that the animals harbor healthy-like microbiota.

The link between microbiota and aging is still poorly understood. However, it has been reported that agerelated differences in the microbiota composition could be associated with immunosenescence [39] and increased frailty [40]. A recent study has shown increased microbial loads in aged Drosophila, which was associated with agerelated dysplasia [41]. In contrast to human and mice that harbor $10^{8}-10^{12}$ and $10^{6}-10^{9}$ c.f.u./g, respectively [42, 43], the quantity of the microbiota of the naked mole-rat was lower, ranging from $10^{2}$ to $10^{5}$ c.f.u./g when verified by cultivation. However, diet intervention could potentially have effect in a general population of microorganism of the rodent [44]. We may also expect a considerable higher diversity of microbes when using more sensitive approaches such as $16 \mathrm{~S}$ rRNA sequencing. 
Early in life, exposure to microbes is known to shape the immune system [45]. The gastrointestinal tract immune network includes neutrophils and regulatory T-cells which communicate with the commensal microbiota. Recent data suggest that commensal bacteria-host crosstalk is continuous and reciprocal throughout life [46]. Enrichment of facultative anaerobes, notably pathobionts, is associated with an enhanced inflammatory status, as determined by inflammatory markers such as IL-6 and IL-8 in blood. Especially, chronic inflammation is known to be associated with metastasizing of tumor cells [47].

These finding forced us to analyze the microbes of the naked mole-rats' intestine with respect to their capability of stimulating inflammatory cytokines in blood. Overall, naked mole-rat microbes were found to be less stimulatory of inflammatory cytokines like IL-1 $\beta$, IL-6 and TNF- $\alpha$ compared with pathobionts from human gut (Fig. 1). Notably, B. megaterium which constitutes the most abundant species (45.2 \%) in the naked molerat intestine seems to induce the least inflammatory response. Whether this has biological implications for the animal's health needs further investigation. Harboring of abundant $B$. megaterium in the gut of naked mole-rats might not be surprising as they are very likely to acquire it from the soil due to their subterranean lifestyle. This bacterium is a common gram-positive, mainly aerobic, spore forming, soil bacterium, which is currently widely used in the field of biotechnology for recombinant protein production [48]. B. megaterium is used to produces penicillin amidase (essential for the synthesis of $\beta$-lactam antibiotics), various amylases, pyruvate, vitamin B12, as well as further unusual enzymes and components, which provide various health benefits such as playing a key role in several metabolic pathways, as endogenous scavenger of certain reactive oxygen species, being involved in DNA repair and synthesis, epigenetic gene regulation, and possessing antifungal and antiviral properties [49-51]. In addition, Paenibacillus spp. was among frequently identified isolates from the gut of naked mole-rats which are known to produce a polymyxin-like antibiotic that is effective against most gram-negative bacteria [52]. This might suggest that B. megaterium and Paenibacillus spp. are beneficial gut symbionts of naked mole-rat. Thus, the presence of these bacteria may probably contribute to the naked mole-rat's resistance to various diseases, which however, needs to be proved yet.

In humans first colonization of the gut occurs during birth. In naked mole rat there is an additional delivery of bacteria to the pups by coprophagy [8]. This may provide pups with endosymbiotic gut flora and transitional source of food. Against this background and the life in a very confined space it is hard to understand the microbial diversity found in the animals in our study. However, as deduced from human studies it is quite possible that difference in gut microbial composition may have impact on shaping the behavior of individuals in the colony [53].

Our field study of natural food sources shows that this long-lived rodent has adapted to consume a wide variety of different plant species, many of which contain large quantities of polyphenols. Furthermore, the content and medical importance of each plant were systematically reviewed and shows that the plant-derived diet of wild naked mole-rats is rich in various anti-oxidants, antiinflammatory, anti-cancer and anti-microbial agents (Additional file 1: Table S1). Despite the fact that the underlying mechanisms are not yet fully understood, recent evidence exists that polyphenols may actively contribute to the prevention of certain illnesses such as cardiovascular and chronic intestinal diseases. Likewise, many studies emphasize the role of polyphenols in prevention of oxidative stress in the pathogenesis of agerelated human diseases. Polyphenols have been shown to scavenge free radicals and protect cell constituents against oxidative damage [54]. Oral administration of polyphenols to rats limits DNA oxidative damage in caeca mucosal cells and can act as a pro-oxidant, thereby inducing apoptosis and reducing the tumor incidence and growth [55-57]. However, the relationship between phenolic compounds and microbiota in terms of health benefits is still poorly understood [58]. Nonetheless, polyphenols have been shown to inhibit the adherence of potentially pathogenic microbes to host cells, while enhancing the proliferation and adhesion of beneficial probiotic bacteria thereby contributing to sustain gut health [59]. Additionally, the consumption of polyphenols has a prebiotic effect on the gut microbiota [60]. In this line, the polyphenol-rich natural diet of wild naked mole-rats in combination with various other plant constituents might contribute to their astonishing resistance to various diseases and their healthy ageing. Therefore, it is not surprising, that as far as longevity is concerned, recent studies revealed that the microbiota composition in individual 'centenarianas' showed tenfold increase in Eubacterium limosum $[39,61]$ that is an anaerobic acetogenic bacterium producing acetate, butyrate, ethanol and vitamin B12.

\section{Conclusion}

In summary, the cultivable gut flora of the naked molerat is composed of a microbiota that is low in number, but diverse and dominated mainly by $B$. megaterium. Our finding that naked mole-rats consume polyphenolrich plants suggests that it could exert a protective effect against different diseases and aging. 


\section{Additional file}

Additional file 1: Table S1. Biochemical contents of food-plants consumed by naked mole-rats in the wild and their medical significance. The table demonstrates naturally occurring plant species consumed by the rodent in the wild life and bioactive constituents of the plants including their medical significance. Naked mole-rats were obtained from wild and housed in a colony of 20 animals. Feeding trials were done by offering of different fresh plant species that are proximate to the habitat of the animal. The biochemical constituents and their medicinal importance of naturally occurring plant species consumed by the rodent in the wild were systematically reviewed. The main diet of the animal is assigned with double asterisk $\left(^{* *}\right)$ and rarely consumed plant species are those with a single asterisk $\left(^{*}\right)$.

\section{Abbreviations}

LPS: lipopolysaccharide; RPMI: Roswell Park Memorial Institute; CBA: cytometry bead array; c.f.u.: colony-forming unit; spp.: species; FACS: fluorescenceactivated cell sorting; MALDI-TOF: matrix-assisted laser desorption ionization time-of-flight; CHCA: a-cyano-4-hydroxycinnamic acid; IL: interleukin; TNF: tumor necrosis factor.

\section{Authors' contributions}

$T D, G B$ and $B K$ designed the experiment and TD characterized the microbes. $\mathrm{SH}, \mathrm{TBH}, \mathrm{MM}, \mathrm{TD}, \mathrm{AL}$ and $\mathrm{GB}$ took part in the animal specimen collection. SR critically reviewed plant constituents and their medical importance. SY, DW and $\mathrm{AL}$ involved in the rats' habitat and diet consumption assessment in the wild. RT, TBH, KH, MP took part in manuscript revision. TD and GB compiled the data and wrote the manuscript. All authors read and approved the final manuscript.

\section{Author details}

${ }^{1}$ Medical Faculty, Institute of Biochemistry, University of Leipzig, Johannisallee 30, 04103 Leipzig, Germany. ${ }^{2}$ Medical Faculty, Institute of Medical Microbiology, University of Leipzig, Leipzig, Germany. ${ }^{3}$ Institute of Pharmacy, University of Leipzig, Leipzig, Germany. ${ }^{4}$ Department of Visceral, Transplantation, Thoracic and Vascular Surgery, University Medical Center Leipzig, University of Leipzig, Leipzig, Germany. ${ }^{5}$ Department of Reproduction Management, Leibniz-Institute for Zoo and Wildlife Research, Berlin, Germany. ${ }^{6}$ Leibniz Institute on Aging-Fritz Lipmann Institute, Jena, Germany. ${ }^{7}$ College of Natural Sciences, Addis Ababa University, Addis Ababa, Ethiopia. ${ }^{8}$ College of Veterinary Medicine and Agriculture, Addis Ababa University, Addis Ababa, Ethiopia. ${ }^{9}$ College of Medicine and Health Sciences, Bahir Dar University, Bahir Dar, Ethiopia.

\section{Acknowledgements}

We gratefully acknowledge Angelika Schäfer and Heike Knaack for her excellent technical assistance and Senait Likasa for excellent animal keeping. We also thank Mohammed Shubo from Addis Ababa University for assisting us in the field. We thank the technicians of the Institute of Medical Microbiology, Faculty of Medicine, University of Leipzig for the assistance during microbial identification. We acknowledge support from the German Research Foundation (DFG) and University of Leipzig within the program of Open Access Publishing.

\section{Competing interests}

The authors declare that they have no competing interests.

\section{Availability of data and materials}

The dataset supporting the conclusions of this article is included within the article and its additional file, and is available upon request to the corresponding author.

\section{Funding}

GB, RT were supported by Grants of the Europäischer Sozialfond ESF (100098250). TD was supported by Katholischer Akademischer Ausländer Dienst (KAAD). TBH, SH, and MM were supported by the Leibniz Association
(SAW-2012-FLI-2). The funding bodies were not involved in the design of the study and collection, analysis, and interpretation of data and in writing the manuscript.

\section{Received: 22 April 2016 Accepted: 16 May 2016}

Published online: 28 May 2016

\section{References}

1. Cenit MC, Matzaraki V, Tigchelaar EF, Zhernakova A. Rapidly expanding knowledge on the role of the gut microbiome in health and disease. Biochim Biophys Acta. 2014;1842:1981-92.

2. lida N, Dzutsev A, Stewart CA, Smith L, Bouladoux N, Weingarten RA, et al. Commensal bacteria control cancer response to therapy by modulating the tumor microenvironment. Science. 2013;342:967-70.

3. Clemente JC, Ursell LK, Parfrey LW, Knight R. The impact of the gut microbiota on human health: an integrative view. Cell. 2012;148:1258-70.

4. Everard A, Cani PD. Diabetes, obesity and gut microbiota. Best Pract Res Clin Gastroenterol. 2013;27:73-83.

5. Zackular JP, Baxter NT, Iverson KD, Sadler WD, Petrosino JF, Chen GY, et al. The gut microbiome modulates colon tumorigenesis. mBio. 2013;4:e00692-13.

6. Alkanani AK, Hara N, Gottlieb PA, Ir D, Robertson CE, Wagner BD, et al. Alterations in intestinal microbiota correlate with susceptibility to type 1 diabetes. Diabetes. 2015;64:3510-20.

7. Kang S, Denman SE, Morrison M, Yu ZT, Dore J, Leclerc M, et al. Dysbiosis of fecal microbiota in Crohn's disease patients as revealed by a custom phylogenetic microarray. Inflamm Bowel Dis. 2010;16:2034-42.

8. Sherman PW, Jarvis JUM, Alexander RD. The biology of the naked molerat. 1st ed. Princeton, NJ: Princeton University Press; 1991.

9. Delaney MA, Ward JM, Walsh TF, Chinnadurai SK, Kerns K, Kinsel MJ, et al. Initial case reports of cancer in naked mole-rats (Heterocephalus glaber). Vet Pathol. 2016;53:691-6.

10. Lewis KN, Andziak B, Yang T, Buffenstein R. The naked mole-rat response to oxidative stress: just deal with it. Antioxid Redox Signal. 2013;19:1388-99.

11. Buffenstein R. The naked mole-rat: a new long-living model for human aging research. J Gerontol A Biol Sci Med Sci. 2005;60:1369-77.

12. Hollenbach M, Hintersdorf A, Huse K, Sack U, Bigl M, Groth M, et al. Ethyl pyruvate and ethyl lactate down-regulate the production of proinflammatory cytokines and modulate expression of immune receptors. Biochem Pharmacol. 2008;76:631-44.

13. Paton A, Harley M, Harley R, Weeks S. A revision of Endostemon (Labiatae). Kew Bull. 1994:49:673-716.

14. Berger A. About the systematic classification of the genus Aloe. Bot Yearb Syst Plant Hist Plant Geogr. 1905:36:36-62.

15. Tap J, Mondot S, Levenez F, Pelletier E, Caron C, Furet JP, et al. Towards the human intestinal microbiota phylogenetic core. Environ Microbiol. 2009;11:2574-84

16. Fisher K, Phillips C. The ecology, epidemiology and virulence of Enterococcus. Microbiology. 2009;155:1749-57.

17. Heyrman J, Logan NA, Rodriguez-Diaz M, Scheldeman P, Lebbe L, Swings $J$, et al. Study of mural painting isolates, leading to the transfer of 'Bacillus maroccanus' and 'Bacillus carotarum' to Bacillus simplex, emended description of Bacillus simplex, re-examination of the strains previously attributed to 'Bacillus macroides' and description of Bacillus muralis sp. nov. Int J Syst Evol Microbiol. 2005;55:119-31.

18. Hong HA, Khaneja R, Tam NM, Cazzato A, Tan S, Urdaci M, et al. Bacillus subtilis isolated from the human gastrointestinal tract. Res Microbiol. 2009;160:134-43.

19. Cornelison CT, Keel MK, Gabriel KT, Barlament CK, Tucker TA, Pierce GE, et al. A preliminary report on the contact-independent antagonism of Pseudogymnoascus destructans by Rhodococcus rhodochrous strain DAP96253. BMC Microbiol. 2014;14:246.

20. Geyid A, Abebe D, Debella A, Makonnen Z, Aberra F, Teka F, et al. Screening of some medicinal plants of Ethiopia for their anti-microbial properties and chemical profiles. J Ethnopharmacol. 2005;97:421-7.

21. Giday M, Teklehaymanot T, Animut A, Mekonnen Y. Medicinal plants of the Shinasha, Agew-awi and Amhara peoples in northwest Ethiopia. J Ethnopharmacol. 2007;110:516-25. 
22. Akor J, Anjorin T. Phytochemical and antimicrobial studies of Commiphora africana root extracts. Int J Agric Biol. 2009;11:795-7.

23. Ayoub S. Polyphenolic molluscicides from Acacia nilotica. Planta Med. 1984;50:532.

24. Debella A, Haslinger E, Kunert O, Michl G, Abebe D. Steroidal saponins from Asparagus africanus. Phytochemistry. 1999;51:1069-75.

25. Humphry CM, Clegg MS, Keen CL, Grivetti LE. Food diversity and drought survival. The Hausa example. Int J Food Sci Nutr. 1993;44:1-16.

26. Ma J, Jones SH, Hecht SM. A dihydroflavonol glucoside from Commiphora africana that mediates DNA strand scission. J Nat Prod. 2005;68:115-7.

27. Mueller-Harvey I, Hartley RD, Reed JD. Characterisation of phenolic compounds, including flavonoids and tannins, of ten Ethiopian browse species by high performance liquid chromatography. J Sci Food Agric. 1987;39:1-14

28. Oketch-Rabah H, Dossaji S, Christensen SB, Frydenvang K, Lemmich E, Cornett C, et al. Antiprotozoal compounds from Asparagus africanus. J Nat Prod. 1997;60:1017-22.

29. Paton AJ, Springate D, Suddee S, Otieno D, Grayer RJ, Harley MM, et al. Phylogeny and evolution of basils and allies (Ocimeae, Labiatae) based on three plastid DNA regions. Mol Phylogenet Evol. 2004;31:277-99.

30. Yamamoto Y, Gaynor RB. Therapeutic potential of inhibition of the NFkappaB pathway in the treatment of inflammation and cancer. J Clin Invest. 2001;107:135-42

31. Cushnie T, Lamb AJ. Recent advances in understanding the antibacterial properties of flavonoids. Int J Antimicrob Agents. 2011;38:99-107.

32. Hanakahi LA, Bartlet-Jones M, Chappell C, Pappin D, West SC. Binding of inositol phosphate to DNA-PK and stimulation of double-strand break repair. Cell. 2000;102:721-9.

33. Wu GD, Lewis JD. Analysis of the human gut microbiome and association with disease. Clin Gastroenterol Hepatol. 2013;11:774-7.

34. Lakritz JR, Poutahidis T, Levkovich T, Varian BJ, Ibrahim YM, Chatzigiagkos A, et al. Beneficial bacteria stimulate host immune cells to counteract dietary and genetic predisposition to mammary cancer in mice. Int J Cancer. 2014;135:529-40.

35. Fisher GJ. Cancer resistance, high molecular weight hyaluronic acid, and longevity. J Cell Commun Signal. 2015;9:91-2.

36. Arumugam M, Raes J, Pelletier E, Le Paslier D, Yamada T, Mende DR, et al. Enterotypes of the human gut microbiome. Nature. 2011;473:174-80.

37. Serban DE. Microbiota in inflammatory bowel disease pathogenesis and therapy: is it all about diet? Nutr Clin Pract. 2015;30:760-79.

38. Madigan MT. Brock biology of microorganisms. 11 th ed. New Jersey: Pearson Prentice Hall, SciELO Espana; 2006.

39. Biagi E, Nylund L, Candela M, Ostan R, Bucci L, Pini E, et al. Through ageing, and beyond: gut microbiota and inflammatory status in seniors and centenarians. PLoS One. 2010;5(5):e10667.

40. O'Toole PW, Jeffery IB. Gut microbiota and aging. Science. 2015;350(6265):1214-5.

41. Guo L, Karpac J, Tran SL, Jasper H. PGRP-SC2 promotes gut immune homeostasis to limit commensal dysbiosis and extend lifespan. Cell. 2014;156:109-22.

42. Ley RE, Peterson DA, Gordon Jl. Ecological and evolutionary forces shaping microbial diversity in the human intestine. Cell. 2006;124:837-48.
43. Dubos R, Savage D, Schaedler R. The indigenous flora of the gastrointestinal tract. Dis Colon Rectum. 1967;10:23-34.

44. Buffenstein R, Yahav S. The effect of diet on microfaunal population and function in the caecum of a subterranean naked mole-rat, Heterocephalus glaber. Br J Nutr. 1991;65:249-58.

45. Maynard CL, Elson CO, Hatton RD, Weaver CT. Reciprocal interactions of the intestinal microbiota and immune system. Nature. 2012:489:231-41.

46. Claesson MJ, Jeffery IB, Conde S, Power SE, O'Connor EM, Cusack S, et al. Gut microbiota composition correlates with diet and health in the elderly Nature. 2012;488:178-84.

47. Fischer-Fodor E, Miklasova N, Berindan-Neagoe I, Saha B. Iron, inflammation and invasion of cancer cells. Clujul Med. 2015;88:272-7.

48. Vary PS, Biedendieck R, Fuerch T, Meinhardt F, Rohde M, Deckwer W-D, et al. Bacillus megaterium - from simple soil bacterium to industrial protein production host. Appl Microbiol Biotechnol. 2007;76:957-67.

49. Bunk B, Schulz A, Stammen S, Münch R, Warren MJ, Rohde M, et al. A short story about a big magic bug. Bioeng Bugs. 2010;2:1-7.

50. Ames BN, Wakimoto P. Are vitamin and mineral deficiencies a major cancer risk? Nat Rev Cancer. 2002;2:694-704

51. Huang CY, Kuo WT, Huang YC, Lee TC, Yu LCH. Resistance to hypoxiainduced necroptosis is conferred by glycolytic pyruvate scavenging of mitochondrial superoxide in colorectal cancer cells. Cell Death Dis. 2013;4:e622.

52. Tambadou F, Caradec T, Gagez AL, Bonnet A, Sopena V, Bridiau N, et al. Characterization of the colistin (polymyxin E1 and E2) biosynthetic gene cluster. Arch Microbiol. 2015;197:521-32.

53. DiazHeijtz R, Wang S, Anuar F, Qian Y, Bjorkholm B, Samuelsson A, et al. Normal gut microbiota modulates brain development and behavior. Proc Natl Acad Sci USA. 2011;108:3047-52.

54. Williamson $\mathrm{G}$, Holst B. Dietary reference intake (DRI) value for dietary polyphenols: are we heading in the right direction? Br J Nutr. 2008:99:S55-8.

55. Scalbert A, Morand C, Manach C, Rémésy C. Absorption and metabolism of polyphenols in the gut and impact on health. Biomed Pharmacother. 2002;56:276-82.

56. Lambert JD, Hong J, Yang GY, Liao J, Yang CS. Inhibition of carcinogenesis by polyphenols: evidence from laboratory investigations. Am J Clin Nutr. 2005;81:284S-91S.

57. Caderni G, De Filippo C, Luceri C, Salvadori M, Giannini A, Biggeri A, et al. Effects of black tea, green tea and wine extracts on intestinal carcinogenesis induced by azoxymethane in F344 rats. Carcinogenesis. 2000;21:1965-9.

58. Valdes L, Cuervo A, Salazar N, Ruas-Madiedo P, Gueimonde M, Gonzalez $\mathrm{S}$. The relationship between phenolic compounds from diet and microbiota: impact on human health. Food Funct. 2015:6:2424-39.

59. Parkar SG, Stevenson DE, Skinner MA. The potential influence of fruit polyphenols on colonic microflora and human gut health. Int J Food Microbiol. 2008;124:295-8.

60. Tzounis X, Vulevic J, Kuhnle GG, George T, Leonczak J, Gibson GR, et al. Flavanol monomer-induced changes to the human faecal microflora. Br J Nutr. 2008;99:782-92

61. Bischoff SC. Microbiota and aging. Curr Opin Clin Nutr Metab Care. 2016;19:26-30

\section{Submit your next manuscript to BioMed Central and we will help you at every step:}

- We accept pre-submission inquiries

- Our selector tool helps you to find the most relevant journal

- We provide round the clock customer support

- Convenient online submission

- Thorough peer review

- Inclusion in PubMed and all major indexing services

- Maximum visibility for your research

Submit your manuscript at www.biomedcentral.com/submit 